This is an author produced version of a paper published in Biological Psychiatry. This paper has been peer-reviewed but does not include the final publisher proofcorrections or journal pagination.

Citation for the published paper:

Wennstrom, Malin and Hellsten, Johan and Ekstrand, Joakim and Lindgren, Hanna and Tingstrom, Anders

"Corticosterone-Induced Inhibition of Gliogenesis in Rat Hippocampus is

Counteracted by Electroconvulsive Seizures."

Biol Psychiatry. 2006 Jan 15;59(2):178-86.

http://dx.doi.org/10.1016/j.biopsych.2005.08.032.

Access to the published version may require journal subscription.

Published with permission from: Elsevier 


\title{
Corticosterone-induced inhibition of gliogenesis in rat hippocampus is counteracted by electroconvulsive seizures ${ }^{1}$.
}

\section{Malin Wennström, Johan Hellsten, Joakim Ekstrand, Hanna Lindgren and Anders Tingström}

From the Molecular Psychiatry Unit (MW, JH, JE, HL, AT) Wallenberg Neuroscience Center, Lund, Sweden

\author{
Corresponding author: Anders Tingström, $\mathrm{MD}, \mathrm{PhD}$ \\ Molecular Psychiatry Unit \\ Wallenberg Neuroscience Center, BMC A13 \\ S-22184, Lund, Sweden \\ Phone: +46-(0)46-2220610 \\ Fax:+46-(0)46-2220615 \\ e-mail: anders.tingstrom@mpu.lu.se
}

Number of words in abstract: 200

Number of words in text: $4991 \div$

Number of figures: 6

Number of tables: 2

Keywords: NG2, electroconvulsive seizure, corticosterone, hippocampus, gliogenesis, oligodendrocyte Running title: ECS induce gliogenesis in CORT treated rats

1.This work was supported by the Swedish Research Council No K2002-21X-14264-01A, the Segerfalk Foundation, theSwedish Lundbeck Foundation, the Sjöbring Foundation and the Bror Gadelius Foundation 


\begin{abstract}
Background: Volumetric changes and glial pathology have been reported in the central nervous system (CNS) of patients with depressive disorder, an illness often associated with elevated glucocorticoid levels. Glucocorticoids reduce gliogenesis in the adult rat CNS. Electroconvulsive seizure (ECS)-treatment, an animal model for the antidepressant treatment electroconvulsive therapy, can enhance proliferation of glial cells. This study examined glial cell proliferation in response to ECS in rats whose glucocorticoid levels were elevated to mimic the conditions seen in depression. Methods: Rats were injected daily for seven days with either corticosterone or vehicle. ECS- or sham- treatment was given once daily during the first five days. Proliferating cells in the hippocampus were labeled with bromodeoxyuridine and analyzed for co-labeling with the glial cell markers NG2, Ox42, S-100 $\beta$ and Rip.
\end{abstract}

Results: ECS counteracted the glucocorticoid-induced inhibition of NG2+, Ox42+ and Rip + cell proliferation, and the gliogenesis rate was restored to baseline levels. Volumetric changes in rats treated with ECS were detected.

Conclusion: Our results show that ECS-treatment affects the proliferation of glial cells even in the presence of elevated levels of glucocorticoids. This result adds to an increasing number of studies suggesting that antidepressant treatment can counteract degenerative processes associated with major depression. 


\section{Introduction}

Several studies show that hippocampal volume is reduced in patients with major depression, compared with healthy controls (for review see Sheline 2003). Hippocampal volume is negatively correlated with the total duration of depression (Sheline et al 1999) and with depression-associated cognitive deficits such as memory impairment (Sheline et al 1996; MacQueen et al 2003). Although volume reduction can persist for decades following depressive episodes (Sheline et al 1996; Sheline et al 1999; Bremner et al 2000), a recent study demonstrates that it can be prevented by antidepressant treatment (Sheline et al 2003).

The precise mechanisms by which depression affects hippocampal volume are unknown, but several clinical studies suggest that the glucocorticoid cortisol may be involved. Up to $50 \%$ of depressed patients show elevated levels of circulating cortisol, which can be restored to normal levels with antidepressant treatment (Carroll et al 1976; Dinan 2001). Patients with Cushing's disease (an illness associated with hypercortisolemia) show high rates of depression (Sonino and Fava 2002) and hippocampal atrophy (Starkman et al 1992). Additionally, treatment with cortisol (Brown et al 2004) can lead to depression, and some antiglucocorticoid therapies have antidepressant-like properties (for review see Murphy 1997).

Similar findings have been observed in animal studies. Rats exposed to corticosterone (the cortisol homologue in rat) show depressive behavior (Gregus et al 2005) and significantly reduced hippocampal volume (Sousa et al 1998). Analogously psychosocial stress, which elevates cortisol levels, caused a non-significant trend towards reduced hippocampal volume in tree shrews (Czeh et al 2001). This was reversed by the antidepressant tianeptine (Czeh et al 2001).

The mechanisms behind cortisol-induced hippocampal volume reductions are poorly understood. 
Previous studies focused on the impact of stress on neurons. It was shown that corticosteronetreatment and psychosocial stress down-regulate the neuronal proliferation known to occur in the dentate gyrus of adult rat hippocampus (Cameron and Gould 1994; Czeh et al 2001; McEwan 1999; Hellsten et al 2002; Malberg et al 2003), and that antidepressant drugs could counteract stressmediated inhibition of neurogenesis (Malberg et al 2003, Czeh et al 2001). However, in postmortem studies of patients with a history of affective disorder, or high-dose steroid treatment, no reduction in the number of neurons could be demonstrated (Lucassen et al 2001; Muller et al 2001). This indicates that the tissue atrophy cannot be explained entirely by a stress-induced down-regulation of neurogenesis.

Interestingly, recent postmortem studies of depressed patients reveal a reduction in the number of glial cells in the amygdala and prefrontal cortex (Rajkowska 2000; Bowley et al 2002). These glial cells were identified as oligodendrocytes (Hamidi et al 2004; Uranova et al 2004). It is thus tempting to speculate that the reduction in hippocampal volume seen in depressed patients (Starkman et al 1992; Sheline et al 1996) may partly be due to glial cell loss.

We previously showed that corticosterone-induced inhibition of hippocampal neurogenesis in adult rats can be reversed by electroconvulsive seizure (ECS)-treatment, an animal model for the antidepressant treatment electroconvulsive therapy (ECT), (Hellsten et al 2002). We found that ECStreatment, apart from inducing neurogenesis stimulate proliferation of other cell types in rat hippocampus and amygdala. Many of these cells were identified as chondroitin sulphate proteoglycan NG2 (NG2)-expressing glial cells (Wennstrom et al 2003; Wennstrom et al 2004). Interestingly, a previous study showed that also proliferation of NG2+ cells is down-regulated by corticosterone (Alonso 2000). 
NG2+ cells make up about $7.5 \%$ of all glia in the adult brain (Butt et al 1999); they are antigenically distinct from neurons, astrocytes, resting microglia and mature oligodendrocytes (for a review see Nishiyama et al 1999). As some NG2+ cells still have the capacity to divide, and many of them express markers for immature oligodendrocytes such as platelet-derived growth factor receptor alpha (PDGFR-alpha), and O-antigen 4 (O4), (Levine et al 1993; Nishiyama et al 1996; Reynolds and Hardy 1997), it has been suggested that these cells are oligodendrocyte progenitors. Another indication of a progenitor role is the finding that $\mathrm{NG} 2+$ cells differentiate into oligodendrocytes in vitro (Levine et al 1993). Because of the limited temporal overlap in the expression of progenitor and mature antigens, this has not been directly demonstrated in vivo. However, recent studies have shown that the promoters for 2',3'-cyclic nucleotide 3'-phophodiesterase (CNPase) (Belachew et al 2001), and proteolipid protein (PLP) (Mallon et al 2002), both active in mature oligodendrocytes, are expressed in NG2+ cells. This evidence supports the view that these cells share a lineage relationship with oligodendrocytes.

The observation that oligodendrocyte numbers are reduced in patients with a history of major depression together with our previous results showing increased proliferation of putative oligodendrocyte progenitors after ECS-treatment prompted us to investigate whether ECS-treatment could counteract the reduction in the newly formed NG2-expressing oligodendrocyte progenitors, that is known to occur in corticosterone-treated rats. We furthermore measured the effects of corticosterone- and ECS-treatment on hippocampal volume. 


\section{Methods and materials}

\section{Animals and experimental design}

Adult male Wistar rats (Møllegaard breeding centre, Denmark), weighing $200 \mathrm{~g}$ at the beginning of the study, were used. Three rats were housed in each cage and kept on a $12 \mathrm{~h}$ light-dark cycle with access to food and water ad libitum. Experimental procedures were carried out according to the guidelines set by the Malmö-Lund ethical committee for the use and care of laboratory animals. To assess glial proliferation after corticosterone- and ECS-treatment, a short (S) and long (L) survival study was conducted. The rats ( $\mathrm{S}: \mathrm{n}=23)(\mathrm{L}: \mathrm{n}=24)$ were divided into following groups: (i) seven days of corticosterone injections and five ECS-trials (S: $n=6)$ and (L: $n=6)$; (ii) seven days of corticosterone injections and five sham-trails $(S: n=6)$ and $(L: n=6)$, (iii) five ECS-trails (S: $n=5)$ and (L: $n=6)$; (iv) seven days of vehicle and five sham trails (S: $n=6)$ and (L: $n=6)$ (Figure 1). The rats were weighed every third day in order to monitor the metabolic effects of corticosterone

\section{Administration of electroconvulsive seizures}

For the first five days of the proliferation study, all rats were subjected once daily $(10.00 \mathrm{am})$, to either a single ECS trial or sham treatment. Electric current was delivered via silver electrode ear clips (Somedic Sales AB, Sweden) (50 mA, $0.5 \mathrm{~s}, 50 \mathrm{~Hz}$ unidirectional square wave pulses) (Figure 1). The rats were monitored after the ECS-treatment to ensure that clonic movements of the face and forelimbs occurred for 20-30 s (indicative of limbic seizures). Control rats were sham-treated, that is, handled identically to the ECS-treated rats except that no current was passed. 


\section{Administration of corticosterone}

A stock emulsion of corticosterone (C2505; Sigma-Aldrich, St Louis, MO, USA) (33.3 mg/ml), was prepared daily by vortexing in sesame oil (Sigma-Aldrich) for $10 \mathrm{~min}$, followed by $60 \mathrm{~min}$ of sonication. Before every injection, the emulsion was vortexed briefly and administered as subcutaneous injections in the neck $(40 \mathrm{mg} / \mathrm{kg})$ every 24 hours $(9.00 \mathrm{am})$. This dose is adequate to elevate blood levels of corticosterone over a 24-hour period (Sapolsky et al 1985). Control rats received vehicle injections (sesame oil).

\section{Administration of BrdU}

The thymidine analogue 5-bromo-2'-deoxyuridine (BrdU) (B5002; Sigma-Aldrich) was used as proliferation marker. Others have shown that this method detects cell proliferation rather then DNA repair (Palmer et al 2000; Cooper-Kuhn and Kuhn 2002). BrdU was dissolved in phosphate buffered saline and administered intraperitoneally. All rats in the study received 10 injections of BrdU (50 $\mathrm{mg} / \mathrm{kg}$ ) at 12-hour intervals $(8.00$ am and $8.00 \mathrm{pm})$, from the day 2 to day 6 following the initial ECS treatment (Figure 1).

\section{Tissue preparation}

Twelve hours (S) or three weeks days (L) after the last BrdU-injection, rats were anesthetized with sodium pentobarbital $(60 \mathrm{mg} / \mathrm{ml})$. After the disappearance of nociceptive reflexes, rats were transcardially perfused with $100 \mathrm{ml} 0.9 \%$ saline, followed by $250 \mathrm{ml} 4 \%$ ice-cold paraformaldehyde. Following decapitation, the brain was removed from the skull and postfixed in $4 \%$ paraformaldehyde 
overnight at $4{ }^{\circ} \mathrm{C}$. The adrenal glands were dissected and weighed to assess the degree of atrophy as a measurement of the efficacy of the corticosterone treatment. The brains were left in $30 \%$ sucrose in PBS until they sank, and were then sectioned on a freezing microtome. Forty-micrometer thick coronal sections were cut, between $3.10 \mathrm{~mm}$ to $4.52 \mathrm{~mm}$ relative to the bregma (Paxinos and Watson 1986), and stored in cryoprotectant solution at $-20^{\circ} \mathrm{C}$ until stained.

\section{Antibodies}

The following primary antibodies were used: rabbit anti-NG2 (1:500 gift from Dr Stallcup) directed against the chondroitin sulfate proteoglycan NG2 expressed on glial progenitor cells (Stallcup et al 1987), mouse anti-CD11b (Ox42) which recognizes microglia (Milligan et al 1991), rabbit anti-S100ß directed against astrocyte cellbodies (Boyes et al 1986), mouse anti-Rip (1:1000 Hybridoma Bank, Iowa City, Iowa) against myelin basic protein expressed by mature oligodendrocytes (Friedman et al 1989), rat anti-BrdU (1:100 Oxford Biotechnology, OBT 0030, Kidlington, UK) against bromodeoxyuridine and mouse anti-Ki67 (Novocastra, Newcastle, United Kingdom; cat no. NCLKi67-MM1) directed against a nuclear antigen expressed in all proliferating cells during late gap 1 (G1), DNA-synthesis (S), mitosis (M) and gap $2(\mathrm{G} 2)$ phase of the cell cycle.

\section{Immunohistochemistry}

In order to analyze cell proliferation with Ki67 staining, sections were rinsed $(3 \times 10 \mathrm{~min})$ in $0.02 \mathrm{M}$ potassium phosphate-buffered saline (KPBS) following exposure to blocking solution (KPBS $+5 \%$ normal goat serum (NGS) (S26 Chemicon, Temecula, CA, USA) $+0.25 \%$ Triton X-100) for one hour at room temperature. The sections were then incubated with mouse anti-Ki67 in blocking solution for 40 hours in darkness at $4^{\circ} \mathrm{C}$ and then rinsed in KPBS $+0.25 \%$ Triton X-100 (KPBS +$)(3 \times 10 \mathrm{~min})$ 
before incubation with Cy-3 conjugated goat anti-mouse 1:200 (Jackson, 115165003 Jackson Immuno Research, West Grove, PA, USA) in blocking solution for 24 hours in darkness at $4^{\circ} \mathrm{C}$. After rinsing in KPBS $(3 \times 10 \mathrm{~min})$, sections were mounted on poly-1-lysine coated slides, air-dried, rinsed briefly in $\mathrm{H}_{2} \mathrm{O}$ and cover-slipped with glycerol-based mounting medium.

For double immunofluorescence staining, sections were rinsed $(3 \times 10 \mathrm{~min})$ in KPBS and then incubated in blocking solution (KPBS $+5 \%$ blocking serum (NGS when staining for NG2 or S-100 $\beta$ and normal horse serum (NHS) (Sigma Aldrich, St Louis, Missouri) when staining for Rip or Ox42))+ $0.25 \%$ Triton X-100) for one hour at room temperature. Sections were then incubated with primary antibody in blocking solution for 24 hours at $4^{\circ} \mathrm{C}$. Following this treatment, the sections were rinsed $(3 \times 10 \mathrm{~min})$ with KPBS + and subsequently incubated in blocking solution for 24 hours at $4{ }^{\circ} \mathrm{C}$, either with biotinylated goat anti-rabbit 1:200 (Vector BA-1000, Vector Laboratories Inc, Burlingame, USA) as secondary antibody to detect NG2 or S-100 $\beta$, or with biotinylated horse anti-mouse 1:200 (Vector BA-2001, Vector Laboratories Inc, Burlingame, USA) as secondary antibody to detect Rip or Ox42. Sections were then rinsed $(3 \times 10 \mathrm{~min})$ in KPBS+ before incubation with Alexa 488 1:200 (Molecular Probes, Eugene, OR, USA) in KPBS+ for 24 hours in darkness, at $4{ }^{\circ} \mathrm{C}$. After a KPBS wash $(3 \times 10 \mathrm{~min})$, the sections were fixed in $4 \%$ paraformaldehyde for 10 minutes at room temperature, rinsed $(3 \times 10 \mathrm{~min})$ in $\mathrm{KPBS}$ and then incubated in $1 \mathrm{M} \mathrm{HCl}$ at $65^{\circ} \mathrm{C}$ for 30 minutes. After further rinses in KPBS $(3 \times 10 \mathrm{~min})$, the sections were exposed to blocking solution (KPBS+ and 5\% normal donkey serum (NDS) (Harlan Sera-Lab, Belton, UK)) for one hour in darkness at room temperature and then incubated with rat anti-BrdU in blocking solution for 40 hours in darkness at $4^{\circ} \mathrm{C}$. The sections were then rinsed in KPBS $+(2 \times 10 \mathrm{~min})$, and KPBS,$+ 2 \% \mathrm{NDS}(1 \times 10 \mathrm{~min})$ before incubation with Cy-3-conjugated donkey-anti-rat 1:200 (Jackson 712-165-153, Jackson Immuno Research, West Grove, PA, USA) in blocking solution for 24 hours in darkness at $4^{\circ} \mathrm{C}$. After 
being rinsed in KPBS $(3 \times 10 \mathrm{~min})$, the sections were mounted as described above.

\section{Data quantification and statistical analysis}

Coronal sections through the mid-dorsal hippocampus $(-3.10 \mathrm{~mm}$ to $-4.52 \mathrm{~mm}$ relative to the bregma) (Paxinos and Watson 1986) were analyzed by observers blind to the treatment conditions. Cell proliferation was assessed in the molecular layer (ML), the granule cell layer (GCL) and hilus of the dentate gyrus, with an Olympus AX70 fluorescence microscope fitted with a $40 \times$ objective. BrdU+ and Ki67+ cells were counted in the different dentate gyrus subregions. Every sixth section throughout the mid-dorsal hippocampus (six sections from each animal) was counted, and the values were averaged and expressed as mean cell number section and sub-region. The chondroitin sulfate proteoglycan NG2 is expressed on various cell-types, such as endothelial cells, monocytes, pericytes and oligodendrocyte progenitors. In this study, however, we only counted cells with the specific morphology previous attributed to oligodendrocyte progenitors (Levine et al 1993, Stallcup et al 1987). Total cell numbers were determined using regular fluorescence microscopy. To confirm double staining for BrdU and glial markers, a Leica TCS SL, Spectral Confocal Microscope (Leica Microsystems, Mannheim, Germany), with a 100x oil immersion lens objective and Leica Confocal Software, version 2.61 (Leica Microsystems, Mannheim, Germany) was used. Cells were evaluated in z-series with a minimum of six consecutive optical sections (figure 8). Data are presented as means $+/-$ SEM and were analysed with one-way analysis of variance followed by Fisher's PLSD post-hoc test. Statistical significance was set at $\mathrm{p} \leq 0.05$. 


\section{Volume measurement}

The volume of the sub-regions of the dentate gyrus was estimated using the Cavalieri principle. The ML, GCL and hilus on every second section from each animal were delineated, using CAST-GRID software (Olympus, Albertslund, Denmark) and an Olympus BH-2 microscope with a 10× objective and a CCD-IRIS color video camera. Values of the cross-sectional areas of these regions were obtained. Total volume of the region of interest was calculated as the mean cross-sectional area multiplied by the length of the region sectioned $(1.4 \mathrm{~mm})$. 


\section{Results}

Corticosterone decreases the number of BrdU+ cells in dentate gyrus

Rats given sham/corticosterone-treatment had significantly lower number of bromodeoxyuridine positive (BrdU+) cells in the hilus $(P=0,004)$ of the dentate gyrus compared to sham/vehicle-treated animals (Figure 2). In a two-group comparison (unpaired t-test) between sham/corticosterone-treated and sham/vehicle-treated groups the reduced number of BrdU+ cells was also significant in the molecular layer $(\mathrm{ML})(P=0,003)$.

\section{ECS counteracts corticosterone-mediated reduction in BrdU+ cell number}

Five electroconvulsive seizures (ECS) significantly increased the number of BrdU+ cells in vehicle-injected rats compared to sham/vehicle-treated rats. The increased cell proliferation occurred in all dentate gyrus subfields (ML $(P<0,0001)$; GCL $(P<0,0001)$; hilus $(P<0,0001))$. ECS/corticosterone-treated rats showed a significant increase in the number of BrdU+ cells compared to rats that were sham/corticosterone-treated. In the granule cell layer, ECS-treatment completely abolished the inhibitory effect of corticosterone and also in ML and hilus the number of BrdU+ cells was significantly higher compared to sham/vehicle-treated rats (ML $(P=0,009)$; GCL $(\mathrm{P}<0,0001)$; hilus $(P<0,0001))$ (Figure 2).

\section{BrdU+ cell numbers correlates with number of cells positive for Ki67}

To determine whether the changes in BrdU+ cell numbers seen in ECS and/or corticosteronetreated rats were caused by a direct effect on proliferation, we stained tissue sections with antibodies directed against the endogenous proliferation antigen Ki67. Since this antigen is expressed only during cell division, the Ki67-staining detects only cells proliferating at the time 
of perfusion. The number of Ki67+ cells in sham/corticosterone-treated rats decreased in all dentate gyrus subregions. This result was only significant when the sham/corticosterone-treated group and the sham/vehicle-treated group were analyzed with unpaired t-test $\operatorname{ML}(P=0,036)$; GCL $(\mathrm{P}=0,058)$; hilus $(P=0,024))$ and not when analyzed with multiple comparisons (ML $(P=0,157)$; GCL $(P=0,367)$; hilus $(P=0,216))$ (Figure 2). ECS/vehicle-treatment significantly increased the number of Ki67+ cells in all subregions (ML $(P=0,004)$; GCL $(P<0,001)$; hilus $(P=0,041))$. ECS-treatment also counteracted the corticosterone-induced inhibition of cell proliferation (ML $(P=0,1318)$; GCL $(P<0,001)$; hilus $(P=0,059))$ (Figure 2)

Corticosterone mediated reduction of $\mathrm{NG} 2 / \mathrm{BrdU}+$ cell numbers is counteracted by ECStreatment

In agreement with a previous report (Alonso 2000), sham/corticosterone-treatment significantly reduced the number of $\mathrm{NG} 2+/ \mathrm{BrdU}+$ cells in the $\mathrm{ML}(P=0.044)$ and the hilus of the dentate gyrus $(P$ $=0.039)$, compared with sham/vehicle-treated rats. The number of NG2+/BrdU+ cells in the GCL was not significantly reduced (Figure 3). ECS/vehicle-treatment significantly increased the number of $\mathrm{NG} 2+/ \mathrm{BrdU}+$ cells compared with sham/vehicle-treated rats. The increased proliferation occurred in all dentate gyrus sub-regions $(P<0.0001)$ (Figure 3). Furthermore, ECS -treatment counteracted the inhibitory effect of corticosterone on the NG2+ cell proliferation in the ML and hilus. The number of $\mathrm{NG} 2+/ \mathrm{BrdU}+$ cells was significantly increased compared with both sham/corticosterone-treated rats (ML $(P=0.0001)$; hilus $(P=0.0002))$ and sham/vehicle-treated rats $(\operatorname{ML}(P=0.013)$; hilus $(P=$ 0.020)) (Figure 3). All NG2+ cells had small cell bodies and extensive processes, indicating a nonreactive state (Ong et al 1999). 
Corticosterone and ECS treatment affects the size of the NG2+ cell population

The total number of NG2+ cells decreased significantly after sham/corticosterone treatment in the ML $(P<0.0001)$ and hilus $(P=0.0013)$ of the dentate gyrus compared with sham/vehicle-treatment.

ECS/vehicle-treatment increased the total NG2+ cell population in the ML $(P=0.0001)$, in the GCL $(P=0.0483)$ and in the hilus $(P=0.0001)$. The reduced numbers of NG2 + cells in the ML and hilus of rats treated with corticosterone was counteracted by ECS-treatment, and the population size did not longer differ from sham/vehicle-treated rats (Figure 4).

\section{Corticosterone and ECS-treatment affect the proliferation of microglia but not astrocytes}

A trend towards decreased number of $\mathrm{Ox} 42+/ \mathrm{BrdU}+$ cells in the $\mathrm{ML}(\mathrm{P}=0,440)$ and hilus $(\mathrm{P}=0,421)$ was detected in sham/corticosterone-treated rats. The reduction in BrdU-labelled microglia however reached significance when the groups were analyzed with unpaired t-test (ML $(P=0,017)$; GCL $(P=0,023)$; hilus $(P=0,006))$. The number of $\mathrm{Ox} 42+/ \mathrm{BrdU}+$ cells was significantly increased in all the dentate gyrys subregions (ML $(P<0,001)$; GCL $(P<0,001)$; hilus $(P<0,001))$ of ECS/vehicle -treated rats. ECS-treatments were also able to significantly increase the BrdU-labelled microglia in ML $(P=0,0034)$ of corticosterone-treated rats and the number of $\mathrm{Ox} 42+/ \mathrm{BrdU}+$ cells did not differ from sham/vehicle-treated rats. This was also seen in the GCL $(P=0,002)$ and hilus $(P<0,001)$ when groups were analyzed with unpaired t-test. The total number of Ox $42+$ cells in the ML $(P=0,045)$ and GCL $(P=0,023)$ increased in rats receiving ECS/vehicle-treatment compared to sham/vehicle-treated rats (Figure 4). The vast majority of the microglia had small cell bodies and a highly ramified appearance, indicating a non-reactive state (Streit et al 2002). A small fraction of the BrdU+ cells expressed the astrocyte antigen S-100ß (less than 0,1\%). No significant differences between the groups could be detected (data not shown). 
No change in the number of BrdU+ mature oligodendrocytes after short survival time.

Staining against the oligodendrocyte marker Rip showed that none of the mature oligodendrocytes were BrdU+ in any of the dentate gyrus sub-regions. The total number of Rip + cell bodies did not significantly differ between the different treatment groups (data not shown).

\section{Volume of DG increase in response to ECS treatment}

There was no significant reduction in the volume of either ML, GCL or hilus in sham/corticosteronetreated rats compared to sham/vehicle-treated rats. However, the ML $(P=0.029)$ and hilus $(P=$ 0.003) in sham/corticosterone-treated rats were significantly smaller than in ECS/vehicle-treated animals. Significant differences in ML $(P=0.035)$ and hilar $(P=0.006)$ volumes were also detected between rats receiving ECS/vehicle-treatment and rats receiving ECS/corticosterone-treatment. Hilar volume in ECS/vehicle-treated rats were larger compared to sham/vehicle-treated rats $(P=0.036)$ (Figure 5).

\section{Fate of proliferating cells}

The fate of the proliferating cells was investigated by giving rats five ECS-treatments and/or corticosterone-treatment, with the same procedures as in the study described above, but with a survival time of three weeks. In agreement with previous findings (Wennstrom et al 2003), many of the NG2+/BrdU+ cells retained their NG2+ state. In rats subjected to ECS/vehicle-treatment, we still detected significantly elevated numbers of NG2+/BrdU+ cells compared with controls $(P<0.0001)$. In rats treated with ECS/corticosterone, the number of BrdU-labeled NG2+ cells were not significant different from sham/vehicle-treated rats (Figure 6). The fraction of NG2+/BrdU+ cells out of all BrdU+ cells after three weeks was significantly lower in GCL in all treatment groups compared to the 
same fraction seen in rats with twelve hours survival. This fraction was also decreased in the ML and hilus of sham/corticosterone-treated rats and ECS/vehicle-treated rats (Table 2).

After the three-week survival period, we detected scattered Rip+/BrdU+ cells (oligodendrocytes) in ML and hilus. The number of BrdU-labeled oligodendrocytes was significantly elevated in ML and hilus of rats treated with ECS/vehicle, compared with sham/vehicle-treated rats $(P<0.0001)$, and significantly decreased in ML $(P=0.006)$ and hilus $(P=0.0012)$ of sham/corticosterone-treated rats, compared with sham/vehicle-treated rats. The number of BrdU+/Rip+ cells in ECS/corticosteronetreated rats was not significantly different from the number in sham/vehicle-treated rats (Figure 6). The number of $\mathrm{Ox} 42+/ \mathrm{BrdU}+$ cells was still significantly elevated after three weeks in all dentate gyrus subfields of ECS/vehicle-treated rats compared to sham/vehicle-treated rats (ML $(P<0,0001)$; GCL $(\mathrm{P}<0,0001)$; hilus $(P<0,0001))$ and ECS-treatment led to significantly higher numbers of BrdUlabelled microglia in $\operatorname{ML}(P=0,020)$ and $\operatorname{GCL}(P=0,004)$ of corticosterone-treated rats compared to rats that only received sham/corticosterone treatment (Figure 6). This was also seen in $\mathrm{ML}(\mathrm{P}=0,001)$ when groups were analyzed with unpaired t-test. The fraction of $\mathrm{Ox} 42+/ \mathrm{BrdU}+$ cells out of all BrdU+ cells in sham/vehicle treated rats after three weeks was significantly lower in all dentate gyrus subregions compared to the same fraction in rats with twelve hours survival. This was also seen in the hilus of rats treated with ECS/corticosterone and ECS/vehicle and for the latter group also in GCL (Tabel 2).

\section{Distribution of glial cells}

The NG2+ cells in the hippocampus were located mainly in the molecular layer (ML), hilus and at the border of the GCL (the subgranular zon, SGZ), with the highest density in the hilus (Figure 2). Rip+ cells had a similar distribution pattern as the NG2+ cells. The oligodendrocyte cell bodies were found 
in the ML and hilus, but not in the GCL. The myelinated fibers were mainly found in the ML and hilus, with the densest distribution in the hilus. Ox42+ cells were evenly distributed over the three dentate gyrus subregions (data not shown).

\section{Biological efficacy of the corticosterone treatment}

In comparison with rats treated with sham $/$ vehicle, rats treated with corticosterone $(40 \mathrm{mg} / \mathrm{kg})$ for seven days displayed reduced weight gain and the ratio between the weight of the adrenal glands and body weight decreased (Table 1). The adrenal weight and adrenal weight/body weight ratio were still significantly lower in corticosterone-treated rats after three weeks of survival, whereas the body weight were only significantly lower when the groups were analyzed with unpaired ttest (se Table 1).

\section{Discussion}

The observation that depression is associated with elevated cortisol levels (Carroll et al 1976; Dinan 2001) suggests that animals chronically treated with corticosterone can model some aspects of human depression. This model has been shown to increase depression-like behavior, as assessed by the forced swim test (Gregus et al 2005; Kalynchuk et al 2004). Additionally, it has been reported that corticosterone treatment causes an impairment of declarative memory, also seen in depressed patients, 
(for review see Roozendaal 2002).

It was shown in a previous study that corticosterone treatment suppresses the normal proliferation of NG2+ oligodendrocyte progenitors in rat hippocampus (Alonso 2000). In this study we confirm this finding and additionally show that corticosterone reduce the total number of NG2+ cells in the ML and hilus of the dentate gyrus. Since BrdU-labelling for five days reflects the sum of cells that have divided (and thereby taken up BrdU) minus newborn (BrdU-labelled) cells that have died, we verified the result of total BrdU+ cell number with a second proliferation marker - Ki67. This antigen is only expressed in proliferating cells and this method therefore gives an estimation of the number of proliferating cells at the time of perfusion. The results from the Ki67+ staining show that the reduction in BrdU+ cells seen after corticosterone-treatment reflects a reduction in cell proliferation and not merely death of BrdU+ cells.

The mechanism by which corticosterone affects NG2+ cell proliferation is not well understood, but the presence of mineralcorticoid (MR) and glucocorticoid (GR) receptors on both immature and mature oligodendrocytes (Vielkind et al 1990; Bohn et al 1991) suggests that corticosterone can affect $\mathrm{NG} 2+$ cells directly.

This study appears to be the first to demonstrate that ECS-treatment counteracts the inhibition of $\mathrm{NG} 2+$ cell proliferation by corticosterone, and that the total number of NG2+ cells is returned to baseline levels. The mechanisms responsible for these effects are not known, but either ECStreatment can directly interfere with the suppressive effect of corticosterone by up-regulating NG2cell-mitogens that are down-regulated by corticosterone treatment or the two different treatments 
affect the proliferation of NG2+ cells through independent pathways.

This study also demonstrates that corticosterone treatment decreases the number of BrdU+ microglia. This corresponds well with a previous in vitro study showing that microglia express both GR and MR and that these two receptors regulate microglial cell proliferation (Tanaka et al 1997). The functional significance of the corticosterone-induced down-regulation of microglial proliferation is yet to be determined, but lately the importance of "resting" ramified non-reactive microglia has been discussed. Microglia in this state are thought to play a supportive role of neuronal function and are known to secrete neurotrophic factors (for review see Vilhardt 2005). Previous studies have also shown that microglial processes make direct contacts with NG2+ cells (Nishiyama et al 1997). These observations are indicative of a functional interaction between microglia and $\mathrm{NG} 2+$ glial cells. Indeed, in vitro studies have demonstrated a role for non-reactive microglia in the survival and maturation of oligodendrocyte precursor cells (Nicholas et al 2001).

Postmortem studies of patients with a history of affective disorder show reductions in hippocampal volume. Additionally, attempts to mimic depressive disorders in animals have shown that corticosterone treatment lead to a significant reduction of all dentate gyrus subregions (Sousa et al 1998) and psychosocial stress, which is accompanied by raised cortisol levels, leads to small, but nonsignificant, hippocampal volume reductions in tree shrews (Czeh et al 2001).

In our study, we could not detect any reduction in overall volume of the dentate gyrus after corticosterone treatment. Because the volume reduction in depressed patients is correlated with the severity and duration of the illness, a plausible explanation for our result may be that the corticosterone treatment period (seven days) was too short to give detectable changes. However, ECS/vehicle-treated animals had significantly larger hilar volumes when compared with 
sham/vehicle-treated animals, and significantly larger ML and hilar volumes when compared to sham/corticosterone-treated animals.

The underlying mechanism of the hippocampal volume reduction in depressed patients remains unclear. A recent postmortem study on patients with a history of depression suggests that the hippocampal atrophy might be due to an increased packing density of neurons and glial cells (Stockmeier et al 2004). Another explanation, as mentioned in the introduction, could be that the volume reduction is, at least partly, caused by a reduction in oligodendrocyte numbers (Hamidi et al 2004). With respect to the latter hypothesis, it is interesting to note that the total number of NG2+ cells (thought to be oligodendrocyte progenitors) was reduced in corticosterone-treated rats in this study. It is also notable that the sub-region with the most pronounced volume reduction, the hilus, is also the sub-region with the densest distribution of $\mathrm{NG} 2+$ cells.

In agreement with other studies, we found that many of the NG2+ cells persist in their NG2+ state over a long period (three weeks) (Nishiyama 2001). NG2+ cells have both morphological and functional characteristics of a differentiated cell. The term synantocyte (Butt et al 2002) has been given to this fourth glial cell type distinguished from astrocytes, oligodendrocytes and microglia. Traditionally, as mentioned above, NG2+ cells are regarded as oligodendrocyte progenitors, but the details of the oligodendrocyte lineage are far from clear. Either can NG2-positive synantocytes transdifferentiate and give rise to NG2-negative oligodendrocytes, or do these two glial cell types have a common and presumably NG2-positive progenitor (Nishiyama et al 2002). In our study both the number of $\mathrm{NG} 2+/ \mathrm{BrdU}+$ cells and the fraction of $\mathrm{NG} 2+/ \mathrm{BrdU}+$ cells out of all BrdU + cells is reduced after a three weeks survival period, compared with after twelve hours survival. This finding could be explained by death of some $\mathrm{NG} 2+/ \mathrm{BrdU}+$ cells or by differentiation into a cell type not 
expressing NG2. Our observation that a small number of mature Rip $+/ \mathrm{BrdU}+$ oligodendrocytes is detected in all of the hippocampal sub-regions after three weeks supports the explanation that some of the NG2+ cells had differentiated into oligodendrocytes.

Our study shows that the number of newly formed oligodendrocytes is significantly reduced already after seven days of corticosterone treatment. This result may be explained by the observation that corticosterone suppresses proliferation of $\mathrm{NG} 2+$ cells and thereby decreases the oligodendrocyte progenitor pool. Statistically significant changes after such short time could very well explain the oligodendrocyte reduction that has been observed in patients with many years of depressive illness. The reduction is counteracted by ECS-treatment, which implies that that the loss of oligodendrocytes, as seen in postmortem studies of depressed patients, may be reversed by ECT. Interestingly a recent study shows that frontal white matter reductions in depressed patients are increased by ECT-treatment (Nobuhara et al 2004). Furthermore, one report also indicates that mood stabilizers can prevent the glial reduction found in patients with major depression (Bowley et al 2002).

We can thus conclude that a number of investigators have reported reduced volume of hippocampus and other brain regions in patients with depressive disorders. Postmortem studies have revealed a loss of oligodendrocytes in the amygdala and prefrontal cortex. Here we show for the first time in an animal depression model that reduced gliogenesis is counteracted by electroconvulsive seizures, and that this antidepressant treatment furthermore increases the volume of hippocampal dentate subregions. Glial cell dysfunction may be of central importance in the patophysiology of depression, and further knowledge on how antidepressant treatment affects proliferation, differentiation and survival of different glial cell populations may give clues to new therapeutic strategies. 
Anders Tingström

\section{Acknowledgements}

The authors would also like to thank Dr Bill Stallcup for kindly providing the NG2 antibody. 


\begin{tabular}{|c|c|c|c|c|}
\hline Treatment & EC & SC & EV & SV \\
\hline S: Adrenal weight (mg) & $* 20,52 \pm 1,17$ & $* 17,98 \pm 1,10$ & $* 35,90 \pm 2,00$ & $31,83 \pm 0,99$ \\
\hline Body weight (g) & $* 225,00 \pm 5,53$ & $* 225,00 \pm 3,43$ & $266,60 \pm 4,08$ & $271,00 \pm 7,55$ \\
\hline Adrenal weight : body weight & $* 9,10 \times 10^{5} \pm 4,81 \times 10^{6}$ & $* 8,03 \times 10^{5} \pm 5,82 \times 10^{6}$ & $1,34 \times 10^{5} \pm 6,15 \times 10^{6}$ & $1,17 \times 10^{5} \pm 7,37 \times 10^{6}$ \\
\hline L: Adrenal weight (mg) & $40,00 \pm 2,34$ & $* 34,17 \pm 2,46$ & $49,67 \quad 2,01$ & $48,67 \pm 4,60$ \\
\hline Body weight (g) & $349,17 \pm 7,90$ & $328,33 \pm 6,01$ & $351,67 \pm 0,10$ & $348,33 \pm 5,73$ \\
\hline Adrenal weight : body weight & $1,15 \times 10^{5} \pm 8,04 \times 10^{7}$ & $* 1,04 \times 10^{5} \pm 7,53 \times 10^{7}$ & $1,41 \times 10^{5} \pm 4,29 \times 10^{7}$ & $1,39 \times 10^{5} \pm 1,21 \times 10^{6}$ \\
\hline \multicolumn{5}{|c|}{$\begin{array}{l}\text { Values represent means } \pm \text { SEM Data were analysed with ANOVA and Fischer's PLSD test }(\mathrm{p}<0,05) \text {. Asterisks indicate significant } \\
\text { increase from the control group in the respective region analysed. Abbreviations: S-twelve hours survival study, } \mathbf{L}-\text { three weeks } \\
\text { survival study, EC-electroconvulsive seizures/corticosterone, SC-sham/corticosterone, EV-electroconvulsive seizures/vehicle and } \\
\text { SV-sham/vehicle. }\end{array}$} \\
\hline
\end{tabular}

\section{Table 2}

\begin{tabular}{|c|c|c|c|c|c|c|c|c|}
\hline \multirow{2}{*}{$\begin{array}{l}\text { Study } \\
\text { Treatment }\end{array}$} & \multicolumn{4}{|c|}{ Twelve hours survival } & \multicolumn{4}{|c|}{ Three weeks survival } \\
\hline & EC & SC & EV & SV & EC & SC & EV & SV \\
\hline \multicolumn{9}{|l|}{ ML } \\
\hline $\mathrm{NG} 2+/ \mathrm{BrdU}+$ & $48,53 \pm 1,57$ & $64,38 \pm 7,19$ & $33,15 \pm 5,68$ & $49,68 \pm 4,79$ & $39,97 \pm 6,47$ & $* 5,00 \pm 5,00$ & $* 17,67 \pm 1,22$ & $46,22 \pm 4,36$ \\
\hline $\mathrm{Ox} 42+/ \mathrm{BrdU}+$ & $6,90 \pm 0,71$ & $6,49 \pm 3,12$ & $11,27 \pm 1,27$ & $5,50 \pm 1,17$ & $* 13,55 \pm 2,37$ & $5,35 \pm 3,35$ & $12,89 \pm 1,36$ & $* 14,58 \pm 1,07$ \\
\hline Rip+/BrdU+ & $0,00 \pm 0,00$ & $0,00 \pm 0,00$ & $0,00 \pm 0,00$ & $0,00 \pm 0,00$ & $* 2,30 \pm 0,26$ & $* 1,00 \pm 1,00$ & $* 1,26 \pm 0,20$ & $* 2,72 \pm 0,48$ \\
\hline \multicolumn{9}{|l|}{ GCL } \\
\hline $\mathrm{NG} 2+/ \mathrm{BrdU}+$ & $7,79 \pm 1,20$ & $10,09 \pm 1,46$ & $9,11 \pm 0,65$ & $15,24 \pm 0,83$ & $* 0,01 \pm 0,13$ & $* 0,00 \pm 0,00$ & $* 1,61 \pm 0,21$ & $* 0,71 \pm 0,28$ \\
\hline $\mathrm{Ox} 42+/ \mathrm{BrdU}+$ & $0,33 \pm 0,05$ & $0,27 \pm 0,12$ & $1,97 \pm 0,52$ & $0,83 \pm 0,26$ & $1,00 \pm 0,23$ & $0,29 \pm 0,21$ & $* 3,67 \pm 0,27$ & $* 1,15 \pm 0,13$ \\
\hline Rip+/BrdU+ & $0,00 \pm 0,00$ & $0,00 \pm 0,00$ & $0,00 \pm 0,00$ & $0,00 \pm 0,00$ & $0,00 \pm 0,00$ & $0,00 \pm 0,00$ & $0,00 \pm 0,00$ & $0,00 \pm 0,00$ \\
\hline \multicolumn{9}{|l|}{ Hilus } \\
\hline $\mathrm{NG} 2+/ \mathrm{BrdU}+$ & $46,04 \pm 3,74$ & $66,57 \pm 8,46$ & $46,41 \pm 3,82$ & $46,83 \pm 4,24$ & $29,43 \pm 6,38$ & $* 0,00 \pm 0,00$ & $* 29,50 \pm 2,06$ & $27,92 \pm 5,00$ \\
\hline $\mathrm{Ox} 42+/ \mathrm{BrdU}+$ & $2,62 \pm 0,10$ & $4,25 \pm 7,75$ & $6,86 \pm 1,16$ & $1,71 \pm 0,73$ & $* 4,04 \pm 1,00$ & $10,00 \pm 7,75$ & $* 11,58 \pm 1,32$ & $* 7,96 \pm 1,82$ \\
\hline Rip+/BrdU+ & $0,00 \pm 0,00$ & $0,00 \pm 0,00$ & $0,00 \pm 0,00$ & $0,00 \pm 0,00$ & $* 3,65 \pm 0,44$ & $* 0,00 \pm 0,00$ & $* 2,82 \pm 0,23$ & $* 3,66 \pm 0,35$ \\
\hline
\end{tabular}

Values represent means \pm SEM Data were analysed with ANOVA and Fischer's PLSD test $(\mathrm{p}<0,05)$. Asterisks indicate significant decrease from the study with twelve hours survival in the respective region analysed. Abbreviations: ML-molecular layer, GCL-granular cell layer, ECelectroconvulsive seizures/corticosterone, SC-sham/corticosterone, EV-electroconvulsive seizures/vehicle and SV-sham/vehicle. 


\section{Table legends and Figure legends}

Table 1. Adrenal weight, body weight and the adrenal : body weight ratio

Table 2. Percentage of double labelled cells

Figure 1. Experimental design and group assignment. Rats were divided into four treatment groups: electroconvulsive seizures and corticosterone (EC); sham and corticosterone (SC); Electroconvulsive seizures and vehicle (EV); and sham and vehicle (SV). Rats in groups EC and EV were subjected to a single electroconvulsive seizure-treatment $(\mathbf{E})$ once daily from day 0 to day 4 . Rats in groups EC and SC were subjected to one corticosterone injection daily $(\mathbf{C})$ from day 0 to the day 6 . Sham (S) and vehicle (V) animals were otherwise treated identically as those receiving ECS and corticosterone treatments, respectively. All rats received bromodeoxyuridine (BrdU) injections twice daily from day 2 to day 6 , and were transcardially perfused 12 hours or 21 days after the last BrdU injection.

Figure 2. Bromodeoxyuridine (BrdU)+ and Ki67+ cells in the dentate gyrus of hippocampus. Sham/corticosterone-treatment (SC) significantly decreased the number of BrdU+ cells in the hilus of dentate gyrus. Electroconvulsive seizure/vehicle-treatment (EV) significantly increased the number of BrdU+ and ki67+ cells in all dentate subregions compared to sham/vehicle-treatment (SV), and electroconvulsive seizure /corticosterone-treatment (EC) significantly increased the number of Ki67+ and BrdU+ cells compared to SC and SV. Asterisks indicate significant differences from controls. Diamonds indicate significant differences from SC. Data are presented as means \pm SEM as analyzed with ANOVA and Fischer's PLSD tests. Statistical significance was accepted at $P \leq 0.05$. 
Figure 3. Proliferating NG2+ cells and microglia in the dentate gyrus of hippocampus.

Sham/corticosterone-treatment (SC) reduced the numbers of proliferating NG2+ cells in the molecular layer (ML) and the hilus, compared with sham/vehicle-treated rats (SV). Electroconvulsive seizure/vehicle-treatment (EV) increased the number of BrdU-labeled NG2+ cells and Ox42+ cells in all dentate gyrus sub-regions compared with SV. Electroconvulsive seizure -treatment also counteracted the inhibiting effect of corticosterone (EC) and the number of proliferating NG2+ cells was significantly, higher compared with SV, in all sub-regions of the dentate gyrus. Electroconvulsive seizure-treatment was also able to reverse the negative effect of corticosterone on BrdU+/Ox42+ cell numbers in ML. Asterisks indicate significant differences from SV. Diamonds indicate significant differences from SC. Data are presented as means \pm SEM as analyzed with ANOVA and Fischer's PLSD tests. Statistical significance was accepted at $P \leq 0.05$.

Figure 4. The total number of NG2+ cells decreased significantly in the molecular layer (ML) and hilus after sham/corticosterone-treatment (SC) compared with sham/vehicle-treatment (SV). This decrease was counteracted by electroconvulsive seizures (EC) and the cell numbers returned to normal. Electroconvulsive seizure/vehicle-treatment (EV) significantly increased the total number of $\mathrm{NG} 2+$ cells, whereas a significant increase in Ox42+ cells after EV were only detected in the ML. Asterisks indicate significant differences from SV. Diamonds indicates significant differences from SC. Data are presented as means \pm SEM as analyzed with ANOVA and Fischer's PLSD tests. Statistical significance was accepted at $P \leq 0.05$.

Figure 5. Volume in cubic millimeters of the dentate gyrus subfields; molecular layer (ML), granule cell layer (GCL), and hilus of dentate gyrus. Sham/corticosterone-treatment (SC) did not reduce the 
volume of any of the dentate gyrus subfields compared with sham/vehicle-treated rats (SV). The volumes of the ML and hilus in rats treated with sham/corticosterone (SC) or electroconvulsive seizure/corticosterone (EC) were significantly smaller than in rats treated with electroconvulsive seizures/vehicle (EV). Significantly increased hilar volume was seen in EV compared to SV. Asterisks indicate significant differences from EV. Data are presented as means \pm SEM and were analyzed with ANOVA and Fischer's PLSD tests. Statistical significance was accepted at $P \leq 0.05$.

Figure 6. Bromodeoxyuridine $(\mathrm{BrdU})+$ glial cells after three weeks survival. Rats treated with electroconvulsive seizures/vehicle (EV) had significant more $\mathrm{NG} 2+/ \mathrm{BrdU}+$ and $\mathrm{Ox} 42+/ \mathrm{BrdU}+$ cells in all three dentate gyrus sub-regions compared to sham/vehicle treated rats (SV). The number of Rip+/ BrdU+ cells was significantly increased in the ML and hilus in EV compared with SV. The number of $\mathrm{NG} 2+/ \mathrm{BrdU}+$ and Rip $+/ \mathrm{BrdU}+$ cells in sham/corticosterone-treated rats (SC) was significantly lower in the ML and hilus compared with SV, and this effect was reversed by electroconvulsive seizure-treatment (EC). The number of $\mathrm{Ox} 42+/ \mathrm{BrdU}+$ cells in EC was significantly higher compared to SC and did not differ compared with SV. Asterisks indicate significant differences from SV. Diamonds indicates significant differences from SC. Data are presented as means \pm SEM and were analyzed with ANOVA and Fischer's PLSD tests. Statistical significance was accepted at $P \leq 0.05$.

Confocal reconstructions of bromodeoxyuridine $(\mathrm{BrdU})+$ glial cells in the hilus of dentate gyrus are shown in the right panel. BrdU staining is shown in red whereas NG2 (a) Ox42 (b) and Rip (c) stainings are shown in green. Three orthogonal (xy,xz and yz) planes are shown. Scale bar $=2,5 \mu \mathrm{m}$. 


\section{References}

Alonso G (2000): Prolonged corticosterone treatment of adult rats inhibits the proliferation of oligodendrocyte progenitors present throughout white and gray matter regions of the brain. Glia 31:219-31.

Belachew S, Yuan X, Gallo V (2001): Unraveling oligodendrocyte origin and function by cellspecific transgenesis. Dev Neurosci 23:287-98.

Bohn MC, Howard E, Vielkind U, Krozowski Z (1991): Glial cells express both mineralocorticoid and glucocorticoid receptors. J Steroid Biochem Mol Biol 40:10511.

Bowley MP, Drevets WC, Ongur D, Price JL (2002): Low glial numbers in the amygdala in major depressive disorder. Biol Psychiatry 52:404-12.

Boyes BE, Kim SU, Lee V, Sung SC (1986): Immunohistochemical co-localization of S-100b and the glial fibrillary acidic protein in rat brain. Neuroscience 17:857-65.

Bremner JD, Narayan M, Anderson ER, Staib LH, Miller HL, Charney DS (2000): Hippocampal volume reduction in major depression. Am J Psychiatry 157:115-8.

Brown ES, D JW, Frol A, et al (2004): Hippocampal volume, spectroscopy, cognition, and mood in patients receiving corticosteroid therapy. Biol Psychiatry 55:538-45.

Butt AM, Duncan A, Hornby MF, et al (1999): Cells expressing the NG2 antigen contact nodes of Ranvier in adult CNS white matter. Glia 26:84-91.

Butt AM, Kiff J, Hubbard P, Berry M (2002): Synantocytes: new functions for novel NG2 expressing glia. J Neurocytol 31:551-65. 
Cameron HA, Gould E (1994): Adult neurogenesis is regulated by adrenal steroids in the dentate gyrus. Neuroscience 61:203-9.

Carroll BJ, Curtis GC, Davies BM, Mendels J, Sugerman AA (1976): Urinary free cortisol excretion in depression. Psychol Med 6:43-50.

Cooper-Kuhn CM, Kuhn HG (2002): Is it all DNA repair? Methodological considerations for detecting neurogenesis in the adult brain. Brain Res Dev Brain Res 134:13-21.

Czeh B, Michaelis T, Watanabe T, et al (2001): Stress-induced changes in cerebral metabolites, hippocampal volume, and cell proliferation are prevented by antidepressant treatment with tianeptine. Proc Natl Acad Sci U S A 98:12796-801.

Dinan T (2001): Novel approaches to the treatment of depression by modulating the hypothalamic - pituitary - adrenal axis. Hum Psychopharmacol 16:89-93.

Friedman B, Hockfield S, Black JA, Woodruff KA, Waxman SG (1989): In situ demonstration of mature oligodendrocytes and their processes: an immunocytochemical study with a new monoclonal antibody, rip. Glia 2:380-90.

Gregus A, Wintink AJ, Davis AC, Kalynchuk LE (2005): Effect of repeated corticosterone injections and restraint stress on anxiety and depression-like behavior in male rats. Behav Brain Res 156:105-14.

Hamidi M, Drevets WC, Price JL (2004): Glial reduction in amygdala in major depressive disorder is due to oligodendrocytes. Biol Psychiatry 55:563-9.

Hellsten J, Wennstrom M, Mohapel P, Ekdahl CT, Bengzon J, Tingstrom A (2002):

Electroconvulsive seizures increase hippocampal neurogenesis after chronic corticosterone treatment. Eur J Neurosci 16:283-90.

Kalynchuk LE, Gregus A, Boudreau D, Perrot-Sinal TS (2004): Corticosterone increases depression-like behavior, with some effects on predator odor-induced defensive 
behavior, in male and female rats. Behav Neurosci. 118:1365-77.

Levine JM, Stincone F, Lee YS (1993): Development and differentiation of glial precursor cells in the rat cerebellum. Glia 7:307-21.

Lucassen PJ, Muller MB, Holsboer F, et al (2001): Hippocampal apoptosis in major depression is a minor event and absent from subareas at risk for glucocorticoid overexposure. Am J Pathol 158:453-68.

MacQueen GM, Campbell S, McEwen BS, et al (2003): Course of illness, hippocampal function, and hippocampal volume in major depression. Proc Natl Acad Sci U S A 100:138792.

Malberg JE, Duman RS (2003): Cell proliferation in adult hippocampus is decreased by inescapable stress: reversal by fluoxetine treatment. Neuropsychopharmacology. 28:1562-71.

Mallon BS, Shick HE, Kidd GJ, Macklin WB (2002): Proteolipid promoter activity distinguishes two populations of NG2-positive cells throughout neonatal cortical development. $J$ Neurosci 22:876-85.

McEwen BS (1999): Stress and hippocampal plasticity. Annu Rev Neurosci 22:105-22

Milligan CE, Cunningham TJ, Levitt P (1991): Differential immunochemical markers reveal the normal distribution of brain macrophages and microglia in the developing rat brain. J Comp Neurol 314:125-35.

Muller MB, Lucassen PJ, Yassouridis A, Hoogendijk WJ, Holsboer F, Swaab DF (2001): Neither major depression nor glucocorticoid treatment affects the cellular integrity of the human hippocampus. Eur J Neurosci 14:1603-12.

Murphy BE (1997): Antiglucocorticoid therapies in major depression: a review.

Psychoneuroendocrinology 22 Suppl 1:S125-32. 
Nicholas RS, Wing MG, Compston A (2001): Nonactivated microglia promote oligodendrocyte precursor survival and maturation through the transcription factor NF-kappa B.Eur $J$ Neurosci 13:959-67.

Nishiyama A (2001): NG2 cells in the brain: a novel glial cell population. Hum Cell 14:77-82.

Nishiyama A, Chang A, Trapp BD (1999): NG2+ glial cells: a novel glial cell population in the adult brain. J Neuropathol Exp Neurol 58:1113-24.

Nishiyama A, Lin XH, Giese N, Heldin CH, Stallcup WB (1996): Co-localization of NG2 proteoglycan and PDGF alpha-receptor on O2A progenitor cells in the developing rat brain. J Neurosci Res 43:299-314.

Nishiyama A, Watanabe M, Yang Z, Bu J (2002): Identity, distribution, and development of polydendrocytes: NG2-expressing glial cells. J Neurocytol 31:437-55.

Nishiyama A, Yu M, Drazba JA, Tuohy VK (1997): Normal and reactive NG2+ glial cells are distinct from resting and activated microglia. J Neurosci Res 48:299-312.

Ong WY, Levine JM (1999): A light and electron microscopic study of NG2 chondroitin sulfate proteoglycan-positive oligodendrocyte precursor cells in the normal and kainatelesioned rat hippocampus. Neuroscience 92:83-95.

Palmer TD, Willhoite AR, Gage FH (2000): Vascular niche for adult hippocampal neurogenesis. J Comp Neurol 425:479-94.

Paxinos G, Watson C (1986): The Rat Brain in Stereotactic Coordinates. Sydney: Academic Press Australia.

Rajkowska G (2000): Postmortem studies in mood disorders indicate altered numbers of neurons and glial cells. Biol Psychiatry 48:766-77.

Reynolds R, Hardy R (1997): Oligodendroglial progenitors labeled with the O4 antibody persist in the adult rat cerebral cortex in vivo. $J$ Neurosci Res 47:455-70. 
Roozendaal B (2002): Stress and memory: opposing effects of glucocorticoids on memory consolidation and memory retrieval. Neurobiol Learn Mem 78:578-95.

Sapolsky RM, Krey LC, McEwen BS (1985): Prolonged glucocorticoid exposure reduces hippocampal neuron number: implications for aging. J Neurosci 5:1222-7.

Sheline YI, Gado MH, Kraemer HC (2003): Untreated depression and hippocampal volume loss. Am J Psychiatry 160:1516-8.

Sheline YI, Sanghavi M, Mintun MA, Gado MH (1999): Depression duration but not age predicts hippocampal volume loss in medically healthy women with recurrent major depression. J Neurosci 19:5034-43.

Sheline YI, Wang PW, Gado MH, Csernansky JG, Vannier MW (1996): Hippocampal atrophy in recurrent major depression. Proc Natl Acad Sci U S A 93:3908-13.

Sonino N, Fava GA (2002): Residual symptoms in depression an emerging therapeutic concept. Prog Neuropsychopharmacol Biol Psychiatry 26:763-70.

Sousa N, Madeira MD, Paula-Barbosa MM (1998): Effects of corticosterone treatment and rehabilitation on the hippocampal formation of neonatal and adult rats. An unbiased stereological study. Brain Res. 794:199-210.

Stallcup WB, Beasley L (1987): Bipotential glial precursor cells of the optic nerve express the NG2 proteoglycan. J Neurosci. 7:2737-44.

Starkman MN, Gebarski SS, Berent S, Schteingart DE (1992): Hippocampal formation volume, memory dysfunction, and cortisol levels in patients with Cushing's syndrome. Biol Psychiatry 32:756-65.

Stockmeier CA, Mahajan GJ, Konick LC, Overholser JC, Jurjus GJ, Meltzer HY et al (2004): Cellular changes in the postmortem hippocampus in major depression. Biol Psychiatry. 56:640-50. 
Streit WJ (2002): Microglia as neuroprotective, immunocompetent cells of the CNS. Glia 40:133-9.

Tanaka J, Fujita H, Matsuda S, Toku K, Sakanaka M, Maeda N (1997): Glucocorticoid- and mineralocorticoid receptors in microglial cells: the two receptors mediate differential effects of corticosteroids. Glia 20:23-37.

Uranova NA, Vostrikov VM, Orlovskaya DD, Rachmanova VI, (2004): Oligodendroglial density in the prefrontal cortex in schizophrenia and mood disorders: a study from the Stanley Neuropathology Consortium. Schizophr Res 67:269-75.

Vilhardt F (2005): Microglia: phagocyte and glia cell. Int J Biochem Cell Biol 37:17-21.

Wennstrom M, Hellsten J, Ekdahl CT, Tingstrom A (2003): Electroconvulsive seizures induce proliferation of NG2-expressing glial cells in adult rat hippocampus. Biol Psychiatry 54:1015-24.

Wennstrom M, Hellsten J, Tingstrom A (2004): Electroconvulsive seizures induce proliferation of NG2-expressing glial cells in adult rat amygdala. Biol Psychiatry 55:464-71.

Vielkind U, Walencewicz A, Levine JM, Bohn MC (1990): Type II glucocorticoid receptors are expressed in oligodendrocytes and astrocytes. J Neurosci Res 27:360-73. 


\section{Proliferation study with short survival}

\begin{tabular}{|c|c|c|c|c|c|c|c|c|}
\hline & DO & D1 & $\mathrm{D} 2$ & D3 & D4 & D5 & D6 & D7 \\
\hline Group EC & $E+C$ & $E+C$ & $\mathrm{E}+\mathrm{C}+\mathrm{BrdU}$ & $\mathrm{E}+\mathrm{C}+\mathrm{BrdU}$ & $\mathrm{E}+\mathrm{C}+\mathrm{BrdU}$ & $\mathrm{C}+\mathrm{BrdU}$ & $\mathrm{C}+\mathrm{BrdU}$ & $\dagger$ \\
\hline Group SC & $S+C$ & $S+C$ & $\mathrm{~S}+\mathrm{C}+\mathrm{BrdU}$ & $\mathrm{S}+\mathrm{C}+\mathrm{BrdU}$ & $\mathrm{S}+\mathrm{C}+\mathrm{BrdU}$ & $\mathrm{C}+\mathrm{BrdU}$ & $\mathrm{C}+\mathrm{BrdU}$ & $\dagger$ \\
\hline Group EV & $E+V$ & $E+V$ & $E+V+B r d U$ & $E+V+B r d U$ & $\mathrm{E}+\mathrm{V}+\mathrm{BrdU}$ & $V+B r d U$ & $\mathrm{~V}+\mathrm{BrdU}$ & $\dagger$ \\
\hline Group SV & $S+V$ & $S+V$ & $\mathrm{~S}+\mathrm{V}+\mathrm{BrdU}$ & $S+V+B r d U$ & $\mathrm{~S}+\mathrm{V}+\mathrm{BrdU}$ & $V+B r d U$ & $\mathrm{~V}+\mathrm{BrdU}$ & $\dagger$ \\
\hline
\end{tabular}

\section{Proliferation study with long survival}

\begin{tabular}{|l|c|c|c|c|c|c|c|c|}
\hline & $\mathrm{D} 0$ & $\mathrm{D} 1$ & $\mathrm{D} 2$ & $\mathrm{D} 3$ & $\mathrm{D} 4$ & $\mathrm{D} 5$ & $\mathrm{D} 6$ & $\mathrm{D} 7$ \\
\hline Group EC & $\mathrm{E}+\mathrm{C}$ & $\mathrm{E}+\mathrm{C}$ & $\mathrm{E}+\mathrm{C}+\mathrm{BrdU}$ & $\mathrm{E}+\mathrm{C}+\mathrm{BrdU}$ & $\mathrm{E}+\mathrm{C}+\mathrm{BrdU}$ & $\mathrm{C}+\mathrm{BrdU}$ & $\mathrm{C}+\mathrm{BrdU}$ & \\
\hline Group $\mathrm{SC}$ & $\mathrm{S}+\mathrm{C}$ & $\mathrm{S}+\mathrm{C}$ & $\mathrm{S}+\mathrm{C}+\mathrm{BrdU}$ & $\mathrm{S}+\mathrm{C}+\mathrm{BrdU}$ & $\mathrm{S}+\mathrm{C}+\mathrm{BrdU}$ & $\mathrm{C}+\mathrm{BrdU}$ & $\mathrm{C}+\mathrm{BrdU}$ & \\
\hline Group $\mathrm{EV}$ & $\mathrm{E}+\mathrm{V}$ & $\mathrm{E}+\mathrm{V}$ & $\mathrm{E}+\mathrm{V}+\mathrm{BrdU}$ & $\mathrm{E}+\mathrm{V}+\mathrm{BrdU}$ & $\mathrm{E}+\mathrm{V}+\mathrm{BrdU}$ & $\mathrm{V}+\mathrm{BrdU}$ & $\mathrm{V}+\mathrm{BrdU}$ & \\
\hline Group SV & $\mathrm{S}+\mathrm{V}$ & $\mathrm{S}+\mathrm{V}$ & $\mathrm{S}+\mathrm{V}+\mathrm{BrdU}$ & $\mathrm{S}+\mathrm{V}+\mathrm{BrdU}$ & $\mathrm{S}+\mathrm{V}+\mathrm{BrdU}$ & $\mathrm{V}+\mathrm{BrdU}$ & $\mathrm{V}+\mathrm{BrdU}$ &
\end{tabular}

\begin{tabular}{l|c|c|}
\cline { 2 - 3 } IIII & $\mathrm{D} 27$ & $\mathrm{D} 28$ \\
\cline { 2 - 3 } IIII & \\
\cline { 2 - 3 } IIII & + \\
\cline { 2 - 3 } IIII & + \\
\cline { 2 - 3 } & & + \\
\cline { 2 - 3 } & & $\dagger$ \\
\hline
\end{tabular}




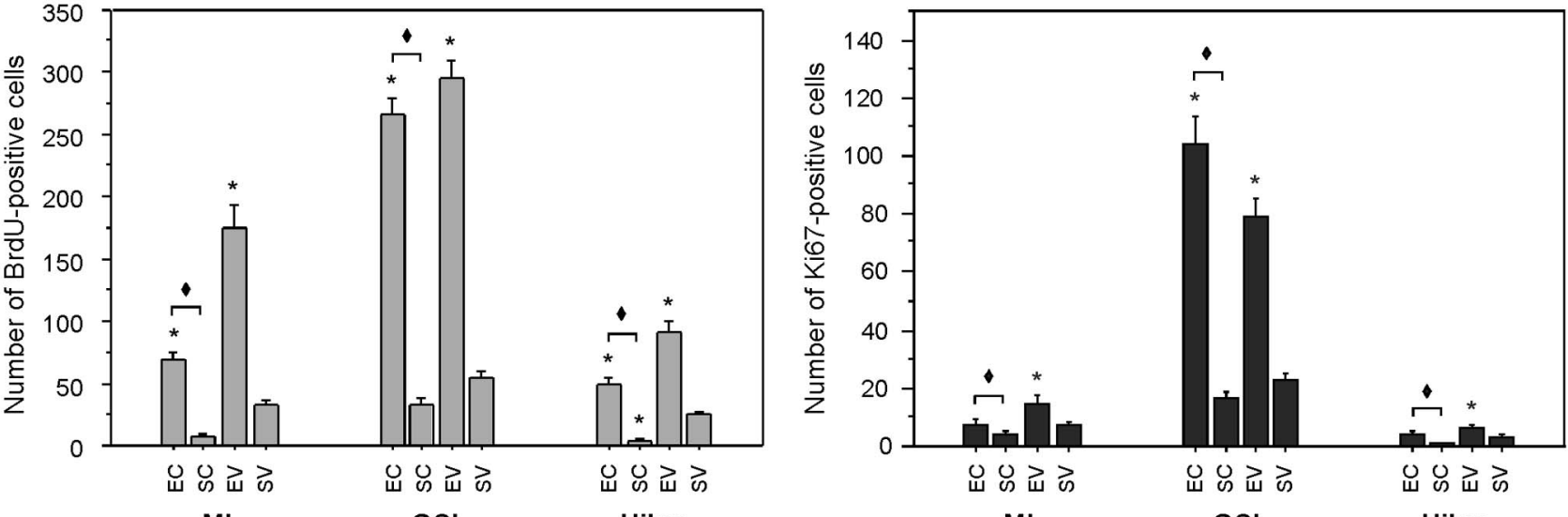



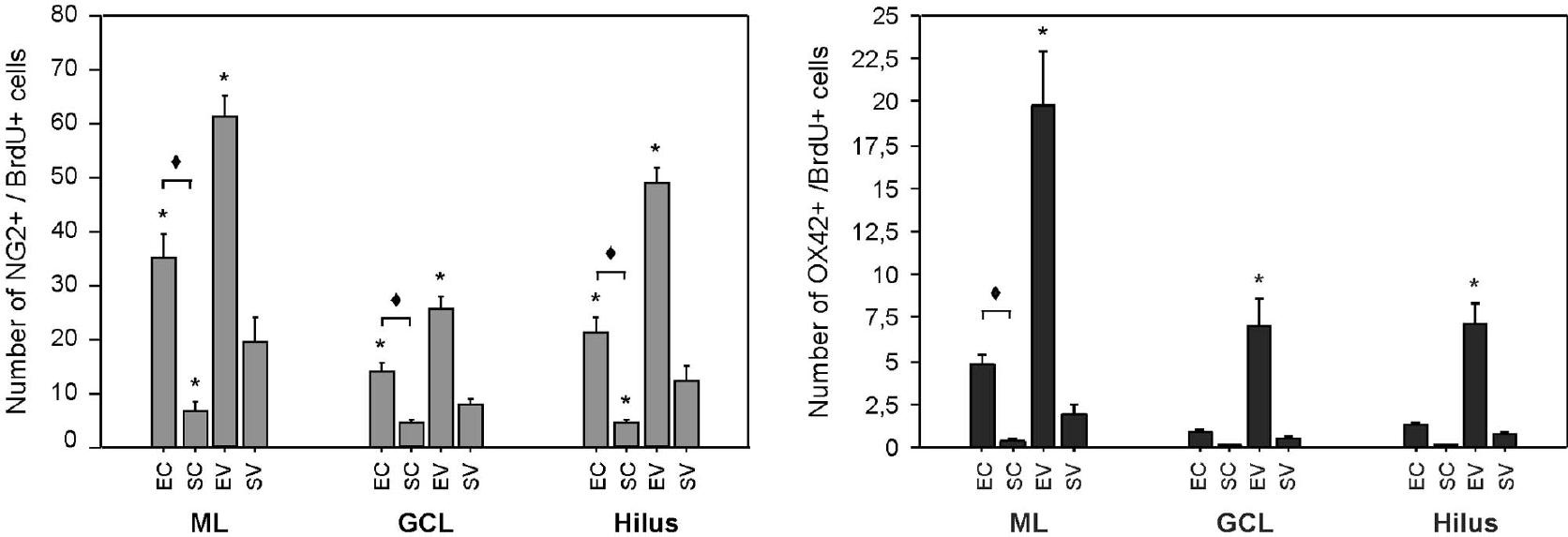


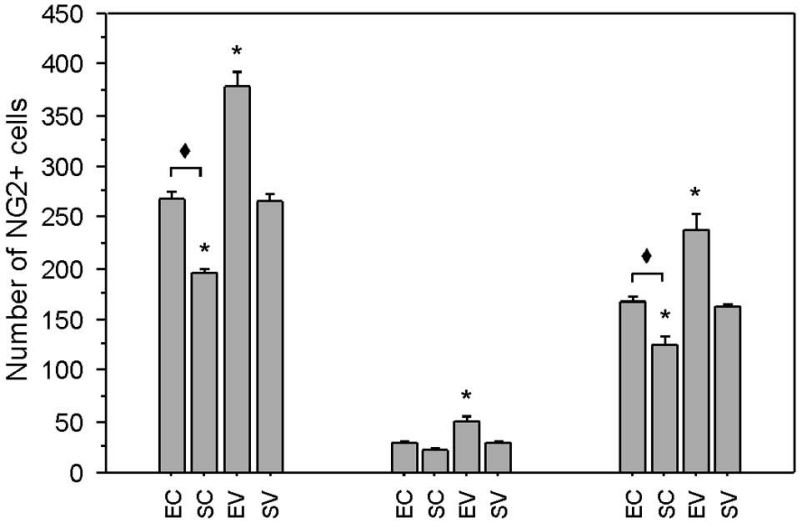

ML
GCL

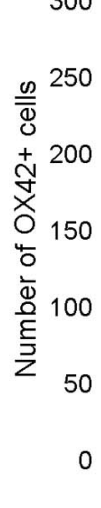

Hilus
ML

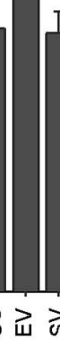

ML

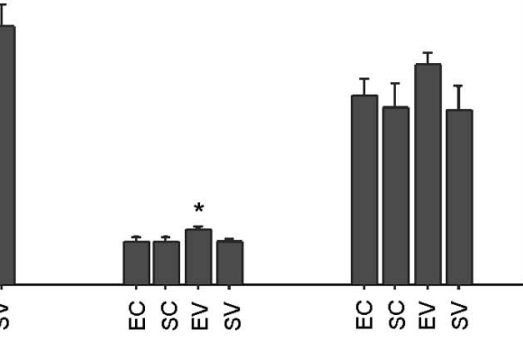

GCL 


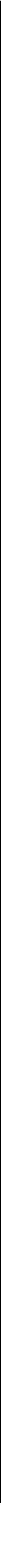


